\title{
INVESTIGATION OF PUMPKIN POD EXTRACT AS CORROSION INHIBITOR FOR CARBON STEEL IN HCL SOLUTION
}

\author{
A. O. Okewale ${ }^{1, *}$ and A. T. Adebayo ${ }^{2}$ \\ 1, 2, DePt. of Chemical Engr'G, Fed. Univ. of Petroleum Resources, EfFurun, DelTA StATE, NIGERIA \\ E-mail addresses: ${ }^{1}$ okewale.akindele@fupre.edu.ng, ${ }^{2}$ adebayo.ayodeji@fupre.edu.ng
}

\begin{abstract}
This work focused on the use of natural, and eco-friendly waste material as an inhibitor for inhibiting carbon steel corrosion. In order to obtain minimum rate of corrosion on carbon steel, optimization of the process factors that affect carbon steel corrosion was undertaken using the Response Surface Methodology (RSM). Three parameters were fluctuated viz; temperature, pumpkin pod extract concentration and time of exposure and their corresponding effects on rate of corrosion of carbon steel were ascertained. The data obtained was fitted to a model that is quadratic which was subsequently validated. The predicted lowest rate of corrosion by the model is $2.5427 \mathrm{~mm} / \mathrm{yr}$ with optimal conditions of $178.07 \mathrm{ppm}$ of pumpkin extract concentration, exposure time of $2.26 \mathrm{hrs}$, and $35.28^{\circ} \mathrm{C}$ of temperature. The conditions were validated in three replicates and corrosion rate of $2.75 \mathrm{~mm} / \mathrm{yr}$ was obtained.
\end{abstract}

Keywords: corrosion, optimization, pumpkin pod, response surface methodology.

\section{INTRODUCTION}

The driving force that causes metals to corrode is a natural consequence of their temporary existence in metallic form [1]. Corrosion is thus inevitable for metals and alloys. Corrosion is the most predominant cause of metal failures today, surpassing other failure modes like fatigue, creep, impact, and others. The cost of corrosion is not only the cost of replacement but additional costs as well such as; Loss of production due to shut down or failure, High maintenance costs, Compliance with environmental and consumer regulations, loss of product quality due to contamination from corrosion of the materials, a high fuel and energy costs as a result of leakage from corroded pipes, extra working capital and larger stocks. The various corrosion prevention techniques available are based on two working principles; alter the component or alter the environment. The alteration of the component can be through design changes which are especially effective where the corrosion is affected by fluid flow characteristics (erosion corrosion, cavitation), presence or absence of gaseous phases (cavitation, pitting), dissimilar metal contact (galvanic corrosion), and solution stagnation (crevice corrosion). Alteration of component also includes alteration of the material of construction, i.e. choosing a different alloy grade for the same component, and the application of coatings. On the other hand alteration of the environment would include the use of inhibitors, or the application of electrochemical protection (anodic or cathodic) [2]. Previous studies have used extract of plant materials on various metals and their alloys in the presence and absence of many inhibitors for corrosion control. Stainless steel $[3 ; 4]$ using pomegranate husk extract, extract of Rhizophora mangle leave, extracts of pomegranate, Alkaloids extracted from isertiacoccinea plant. Mild steel [5 - 13] using the extract of phyllanthhusfraternus extract, extracts of Anacylis pyrethrum leaf, Retamaretam extracts, Saracaindica (Asoka) leaf extracts. Ethanol extracts from leaves, bark, and root of Nauclealatifolia, extract of dodonaeaviscosa leaves, ethanol extracts of Andrographispaniculata (king bitter) Vernoniaamygdalina (bitter leaf). Carbon Steel [14 16] using Reuteralutea (Desf) Maire) Punica plant extract, oil of Thymus Pallidus plant from Morocco. Alluminium and its alloy [17 - 19] using green tea extract, Solanumtrilobatum leaves extract, and Morindacitrifolia leave, M. citrifolia leave extract

* Corresponding author, tel: +234 8069365637 
respectively. Uwah, et a/[20] used copper with extract of Cannabis plant as an inhibitor Pumpkin (Telfairia occidentalis) Pod is an agricultural waste readily available in Nigeria, it is biodegradable, and contain phytochemical constituents such; tannins, flavonoid, steriod, terpenoids, saponin, carbohydrates, amino acids and proteins $[5,21]$. These organic compounds contain polar functions with $\mathrm{N}, \mathrm{S}, \mathrm{O}$ atoms as well as conjugated double bonds or aromatic rings in their molecular structure, which are the major adsorption centre. The use of Pumpkin pod extract as corrosion inhibitor and the statistical analysis of the inhibition process on carbon steel is not available in any open literature to the best of our knowledge, hence the need for this research work. In this work, three parameters namely; temperature, pumpkin pod extract concentration, and time of exposure were optimized. In order to minimize the rate of corrosion of carbon steel, RSM was used using the Box Behnken experimental design to determine the effects of three factors (pumpkin pod extract concentration, temperature, and time of exposure) and their reciprocal effect on rate of carbon steel corrosion. This work established the process conditions in achieving minimum rate of corrosion on carbon steel in acidic environment which could be applied in industrial scale.

\section{MATERIALS AND METHODS}

\subsection{Materials}

Pumpkin pods ( $T$. occidentalis) were obtained from Agbarho Community in Effurun, Delta State, Nigeria. Carbon steel was procured from accredited iron sheet dealer in Effurun and machined in Mechanical Workshop at Federal University of Petroleum Resources, Delta State. HANNA model pH - $211(\mathrm{pH}$ meter), Genlab oven model Mino/75/f (oven), weighing balance of model $(\mathrm{BH}-600)$, and beakers, were employed for this corrosion study.

Hydrochloric acid, acetone, and ethanol solutions used were of analytical grades and were procured from a qualified chemical dealer in Effurun, Delta State, Nigeria. Distilled water was procured from the Department of Chemical Engineering Laboratory, Federal University of Petroleum Resources, Effurun Delta, State, Nigeria for sample preparation and solutions.

\subsection{Methods}

\subsubsection{Pre-treatment of sample and sample characterization}

The samples were thoroughly washed thereafter sun dried and pulverized into powdery form with the aid of laboratory blender. It was then sieved with a sieve of $0.143 \mu \mathrm{m}$ mesh. The sample was later stored in a desiccator prior to use.

\subsubsection{Fourier Transform Infrared Spectroscopy (FTIR)}

Pumpkin pods ( $T$. occidentalis) $0.143 \mu \mathrm{m}$ particle size was observed with FTIR spectroscopy (Buck Scientific model 530) with the range $500-4000 \mathrm{~cm}^{-1}$ (wavelength). The background material used in the analysis is potassium bromate $(\mathrm{KBr})$.

\subsubsection{Extraction of Pumpkin pods ( $T$. occidentalis) extract}

The Pumpkin pods ( $T$. occidentalis) were washed thoroughly with running water to remove debris. The washed samples were sun dried for 14 days and ground to a particle seize of $0.143 \mu \mathrm{m}$. The sample was stored in a desiccator before used. $50 \mathrm{~g}$ of the dried Pumpkin pods ( $T$. occidentalis) powder was transferred into a $500 \mathrm{~mL}$ Soxhlet extractor and $500 \mathrm{~mL}$ of $70 \%$ ethanol reflux continuously for 3 hours at $78^{\circ} \mathrm{C}$. The set-up was placed on a heating mantle and the Pumpkin pods ( $T$. occidentalis) extract was extracted exhaustively by heating the solution. The extract was obtained after recovering ethanol in a Rotary evaporator (model R-210) at $40^{\circ} \mathrm{C}$.

\subsection{Procedure of the experiment}

The gravimetric or weight loss method was used. The corrosion study was carried out using the method described by [22]. The carbon steel was mechanically polished with silicon carbide abrasive paper, degreased with ethanol, washed in distilled water and dried in acetone. Each carbon steel coupon was sized $40 \mathrm{~mm} \times 20 \mathrm{~mm} \times 2 \mathrm{~mm}$. Before polishing, a hole of $0.1 \mathrm{~cm}$ was drilled on each coupon. The coupon was suspended with the aid of a nylon thread in a $100 \mathrm{ml}$ beaker with $100 \mathrm{ml}$ of $1.5 \mathrm{M} \mathrm{HCl}$ at three; different pumpkin pod extract concentrations, exposure time, and temperature.

\subsubsection{Optimization studies of corrosion inhibition process on carbon steel}

Optimization of the process variables affecting the rate of corrosion was carried out using Response Surface Methodology (RSM). The three factors varied were temperature, pumpkin pod extract concentration, and exposure time and their corresponding effects on rate of carbon steel corrosion in acidic medium was investigated. 17 runs of experiments were produced 
using Box Behnken Design (BBD). The model fitness was evaluated using the test of significance and analysis of variance (ANOVA) that is type III. The selected variables pumpkin pod extract concentration, exposure time, temperature represent $X_{1}, X_{2}$, and $X_{3}$ respectively. This is shown in Table 1.

The coefficient of the polynomial model was determined using the multiple regressions as shown in Equation (1).

$\mathrm{Y}=\mathrm{b}_{0}+\sum_{i=1}^{k} \beta_{i} X_{i}+\sum_{i=1}^{k} \beta_{i i} X_{i}^{2}+\sum_{i<j} \beta_{i j} X_{i} X_{j}+e$ (1)

Where, $Y$ is the weight loss, $b_{0}$ is the intercept, $b_{i j}$ is the interaction effect, and $b_{i i}$ denotes the quadratic coefficients of $X_{i}$, and $e$ is the random error [23 - 24]. Design Expert 7.00 software was used to design and analyze the data from the experiment. This is a statistical software package that does design of experiments, comparative tests and optimization of the process variables. It is also used to study the parameters on the yield of a process using the graphical tool.

\subsection{Corrosion rate determination}

The expression for measurement of corrosion rate (C.R) in millimeters penetration per year $(\mathrm{mm} / \mathrm{yr})$ was used to measure the rate of corrosion rate for the specimens, which was expressed in equation 2.

$$
\text { C.R. }=\frac{87.6 \mathrm{w}}{\text { at } \rho}
$$

Where, $\mathrm{w}$ is corrosion weight loss of carbon steel ( $\mathrm{mg}$ ), $a$ is the total surface area of the specimen in $\left(\mathrm{cm}^{2}\right), t$ is the exposure time in hours (hr), and $\rho$ is the density of the specimen $\left(\mathrm{g} / \mathrm{cm}^{3}\right)$.

\section{RESULTS AND DISCUSSION}

\subsection{FTIR analysis of Pumpkin pod ( $T$. occidentalis) extract}

The FTIR spectrum of Pumpkin pods ( $T$. occidentalis) extract is shown in figure 1 . At broad band of $3324 \mathrm{~cm}^{-}$ ${ }^{1}$ corresponds to an alcoholic $-\mathrm{OH}$ stretching group. The peak at $2974 \mathrm{~cm}^{-1}$ can be assigned to alcoholic C$\mathrm{H}$ group. $1639 \mathrm{~cm}^{-1}$ wavelength indicates an aromatic $(C=C)$ stretching while the value of $1728 \mathrm{~cm}^{-1}$ suggest $(\mathrm{C}=0)$ stretching frequency. Aromatic rings due to aromatic skeletal vibrations is noticed at $1508 \mathrm{~cm}^{-1}$ and $1421 \mathrm{~cm}^{-1}$ can be assigned to aromatic rings due to aromatic skeletal vibrations. The broad band of 1329 $\mathrm{cm}^{-1}$ seen in the spectrograph is due to bending vibrations of $\mathrm{OH}$ group while $1209 \mathrm{~cm}^{-1}$ is due to guaicynl ring in conjunction with $\mathrm{C}-\mathrm{O}$ stretching group. The presence of aromatic, and carbonyl groups in the extract suggest that it can be used as an inhibitor.

Table 1: Experimental factors codes and level

\begin{tabular}{lcccc}
\hline Variables & Symbol & $\begin{array}{c}\text { Low Factor } \\
(-1)\end{array}$ & Mid-point Factor $(0)$ & $\begin{array}{c}\text { High Factor } \\
(+1)\end{array}$ \\
\hline Pumpkin pod extract concentration, $(\mathrm{ppm})$ & $\mathrm{X}_{1}$ & 50 & 150 & 250 \\
Exposure time, $(\mathrm{hr})$ & $\mathrm{X}_{2}$ & 2 & 7 & 12 \\
Temperature, $\left({ }^{\circ} \mathrm{C}\right)$ & $\mathrm{X}_{3}$ & 35 & 45 & 55 \\
\hline
\end{tabular}

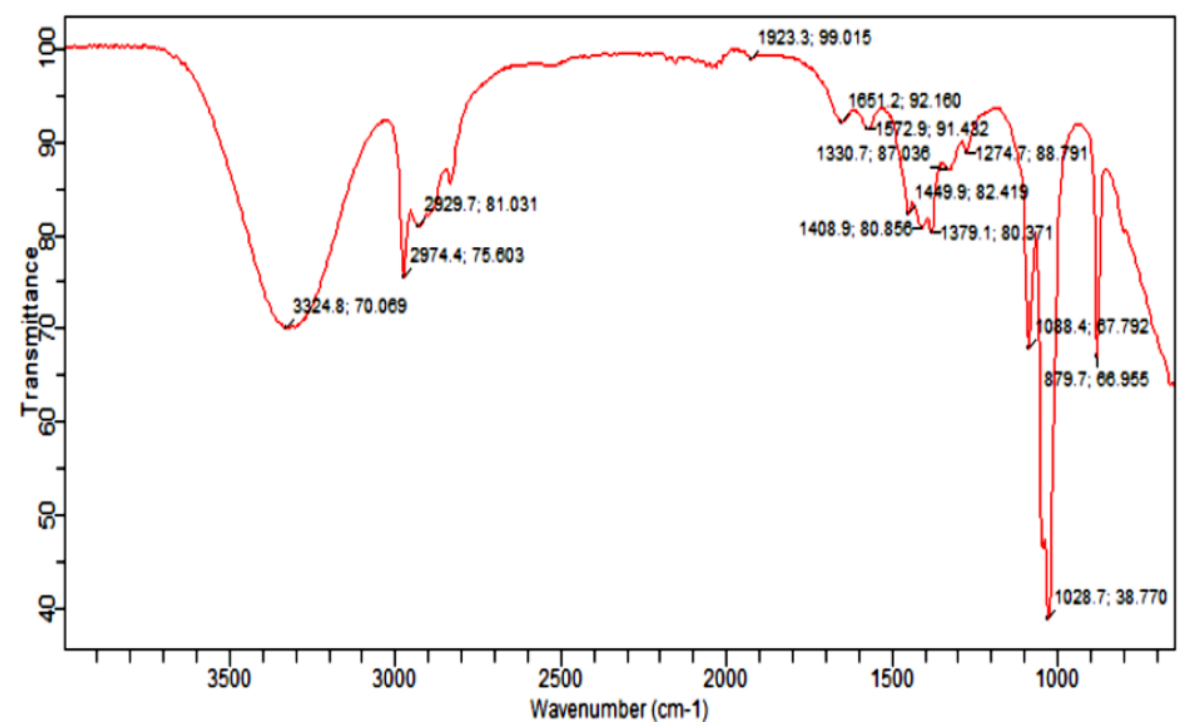

Fig. 1: FTIR spectra of Pumpkin pod extract 
Table 2: ANOVA of Regression Equation Results for Quadratic Model

\begin{tabular}{llllcc}
\hline Sources & Sum of squares & DF & Mean square & F- Value & P - value \\
\hline Model & 2242.23 & 9 & 249.14 & 519.78 & $<0.0001$ \\
Conc. of extract & 106.30 & 1 & 106.30 & 221.78 & $<0.0001$ \\
Exposure time & 897.94 & 1 & 897.94 & 1873.39 & $<0.0001$ \\
Temperature & 946.78 & 1 & 946.78 & 1975.28 & $<0.0001$ \\
Concentration and time & 26.31 & 1 & 26.31 & 54.90 & 0.0001 \\
Conc. and Temp. & 16.35 & 1 & 16.35 & 34.11 & 0.0006 \\
Time and Temp. & 167.40 & 1 & 167.40 & 349.25 & $<0.0001$ \\
Conc. of extract & 15.14 & 1 & 15.14 & 31.60 & 0.0008 \\
Exposure time $^{2}$ & 10.02 & 1 & 10.02 & 20.91 & 0.0026 \\
Temperature & 48.68 & 1 & 48.68 & 101.55 & $<0.0001$ \\
Residual error & 3.36 & 7 & 0.48 & & \\
Lack of fit & 3.34 & 3 & 1.11 & 256.23 & $<0.0001$ \\
Pure error & 0.017 & 4 & 0.004342 & & \\
Corelation Total & 2245.59 & 16 & & & \\
\hline
\end{tabular}

Table 3: Optimization objective

\begin{tabular}{lllc}
\hline Constraints & Goal & Lower limit & Upper limit \\
\hline Concentration of pumpkin extract & in range & 50 & 250 \\
Contact time & in range & 2 & 12 \\
Temperature & in range & 35 & 55 \\
\hline
\end{tabular}

\subsection{Statistical analysis of the Response Surface Methodology Quadratic Model of BBD}

Statistical testing of the quadratic model was done using analysis of variance (ANOVA) as depicted in Table 2. The $F$ - value was used to check the significance of the model. The high $\mathrm{F}$ - value of 519.78 and $p-$ value $<0.0001$ indicated that the quadratic model used is significant. Thus, the data obtained experimentally is well represented by the quadratic model. The standard deviation value of 0.69 is realized as seen in Table 4. The coefficient of determination $\left(R^{2}\right)$ is defined as the ratio of the explained variation to the total variation, and is a measure of the degree of fitness of the model [3].

[25] suggested that a good model fit should yield a coefficient of correlation $\left(R^{2}\right)$ of at least 0.8 . Coefficient of correlation $\left(R^{2}\right)$ value of 0.9985 was obtained for the model which is closer to 1 suggesting that the predicted values are close to the actual values used in the experimental design, signifying that the model is accurate [26]. The results from this investigation showed that the selected factors were sufficiently represented by the obtained model. This also described that there is an actual correlation among the factors selected in the experiment. It showed that $99.85 \%$ of the total variation in the corrosion rate of pumpkin pod extract can be connected experimentally to the studied variables. The $p$ - values was used to check the significance of each of the coefficient in the model. An adequate precision ratio of 80.880 is obtained in this work this indicates an adequate signal to noise ratio. It can also be suggested that the model can be used to navigate the design space. The precision ratio value gotten confirmed the adequacy of the model signal. The goodness - of - fit of the regression equation was measured using the adjusted coefficient of determination $\left(R^{2}\right)$. The predicted $R^{2}$ value of 0.9762 which indicate the model power in response prediction. The coefficient of variation (CV) for the standard deviation of the mean and experimental data is $4.48 \%$. This showed a better reliability and precision of the experiments carried out [27 - 28]. The reproducible of the data value was confirmed from the coefficient of variation value obtained which is lesser than $10 \%$. A p-value lower than 0.05 indicates that the model is statistically significant, whereas a value higher than 0.1000 indicates that the model is not significant [6].The significance of each coefficient is also established using the Probability value ( $P$ - value) and the ratio of the mea square ( $F-$ value) at $5 \%$ confidence level. It can be seen that corrosion of stainless steel using pumpkin pod extract as inhibitor was significantly affected by $\left(X_{1}, X_{2}\right.$, and $\left.X_{3}, p<0.0001\right)$ linear terms but exposure time and temperature has a good synergestic effect on the rate of corrosion. It is obvious that all the interaction terms $\left(X_{1} X_{3}, X_{1} X_{2}\right.$ and $\left.X_{2} X_{3}\right)$ were also significant at the probability level of $(p<0.05)$ but it can be seen that only exposure time and temperature that has positive synergestic effect 
on the rate of carbon steel corrosion likewise all the quadratic terms $\left(\mathrm{X}_{1}{ }^{2}, \mathrm{X}_{2}{ }^{2}\right.$, and $\left.\mathrm{X}_{3}{ }^{2}\right)$ were also significant at the probability level of $(p<0.05)$. This suggest a positive interaction between all the process variables studied which were noted to be the core factors influencing the rate of corrosion, and weight loss of the carbon steel. The Response Surface Methodology (RSM) model for the rate of corrosion of carbon steel using pumpkin pod extract as an inhibitor was optimized using the desirability function of the Response Surface Methodology. The optimum conditions predicted from the quadratic model as shown in Table 3 were pumpkin pod extract concentration (178.07 ppm), exposure time (2.26 hours), and temperature $\left(35.28^{\circ} \mathrm{C}\right)$ that correspond to the corrosion rate of $2.5423 \mathrm{~mm} / \mathrm{yr}$. These values were validated experimentally with an average corrosion rate of $2.75 \mathrm{~mm} / \mathrm{yr}$ from three replicates, this was in good agreement with the optimum result predicted predicted by the regression model. The statistical estimates of the Box Behken design was shown in Table 4.

The experimental testing of full quadratic model is expressed by the second order polynomial equation in term of actual values below:

$\mathrm{Y}=12.24-3.65 \mathrm{x}_{1}+10.59 \mathrm{x}_{2}+10.88 \mathrm{x}_{3}-2.56 \mathrm{x}_{1} \mathrm{x}_{2}-$ $2.02 x_{1} x_{3}+6.47 x_{2} x_{3}+1.90 x_{1}^{2}+1.54 x_{2} 2+3.40 x_{3}{ }^{2}(3)$

where, $Y$ is the rate of corrosion $(\mathrm{mm} / \mathrm{yr}), \mathrm{X}_{1}$ is concentration of pumpkin pod extract $(\mathrm{ppm}), \mathrm{x}_{2}$ is exposure time (hr), and $\mathrm{x}_{3}$ is the temperature $\left({ }^{\circ} \mathrm{C}\right)$.

Table 4: Statistical estimates of BBD

\begin{tabular}{ll}
\hline Parameters & Value \\
\hline Standard deviation & 0.69 \\
Mean & 15.46 \\
Coefficient of variation $(\%)$ & 4.48 \\
$\begin{array}{l}\text { Coefficient of determination } \\
\left(\mathrm{R}^{2}\right)\end{array}$ & 0.99985 \\
$\begin{array}{l}\text { Predicted Coefficient of } \\
\text { determination }\left(\mathrm{R}^{2}\right)\end{array}$ & 0.9762 \\
$\begin{array}{l}\text { Adjusted Coefficient of } \\
\text { determination }\left(\mathrm{R}^{2}\right)\end{array}$ & 0.9966 \\
Adequate precision & \\
\hline
\end{tabular}

The predicted and experimental data of the rate of corrosion $(\mathrm{mm} / \mathrm{yr})$, were investigated also to determine their correlation this is shown in figure 2 . The data points on the plot were discreetly distributed and very close to the horizontal point line. This suggests a very good relationship between the predicted values and experimental values obtained for the response, this also implied the strong predictive power of the model used. This further elucidate the assumptions made that the data can be used to navigate the design space. In addition, a normal plot of residuals between the normal probability (\%) and the internally studentized residuals was also obtained as seen in figure 3 . In this way, the residuals was checked to determine how well the model satisfies the assumptions of analysis of variance (ANOVA), and the internally studentized residuals can be used to measure the standard deviations separating the experimental and predicted values [7]. This suggests a very good relationship between the predicted values and experimental values obtained for the response, this also implied the strong predictive power of the model used. This further elucidate the assumptions made that the data can be used to navigate the design space.

\subsection{Surface Response Plots}

3-D surface response plots were presented in Figures $(4-6)$ based on the analysis of the full quadratic model. It was used to give an important evidence on the system behaviour within the experimental design on the corrosion rate of stainless steel. Figure 4 described the effect of pumpkin pod extract concentration $\left(x_{1}\right)$ and time of exposure $\left(x_{2}\right)$ on the rate of corrosion, it can be seen that the corrosion rate is reduced as pumpkin pod extract concentration is increased with time of exposure. This also affirmed the negative synergy of the time of exposure in the model obtained for carbon steel corrosion. Figure 5 depicted the effect of temperature $\left(x_{3}\right)$, and pumpkin pod extract concentration $\left(x_{1}\right)$, on the rate of corrosion, it was observed that lower temperature and higher pumpkin pod extract concentration favoured a decreased in rate of corrosion on carbon steel. This also confirmed the synergetic effect of these two terms on rate of carbon steel corrosion. Figure 6 showed the effect of exposure time ( $\left.x_{2}\right)$, and temperature $\left(\mathrm{x}_{3}\right)$ on rate of corrosion, it was revealed that the higher temperature with increased in exposure time favoured a higher rate of carbon steel corrosion studied. This also confirmed the synergestic effect of these two variables of the rate of corrosion. 

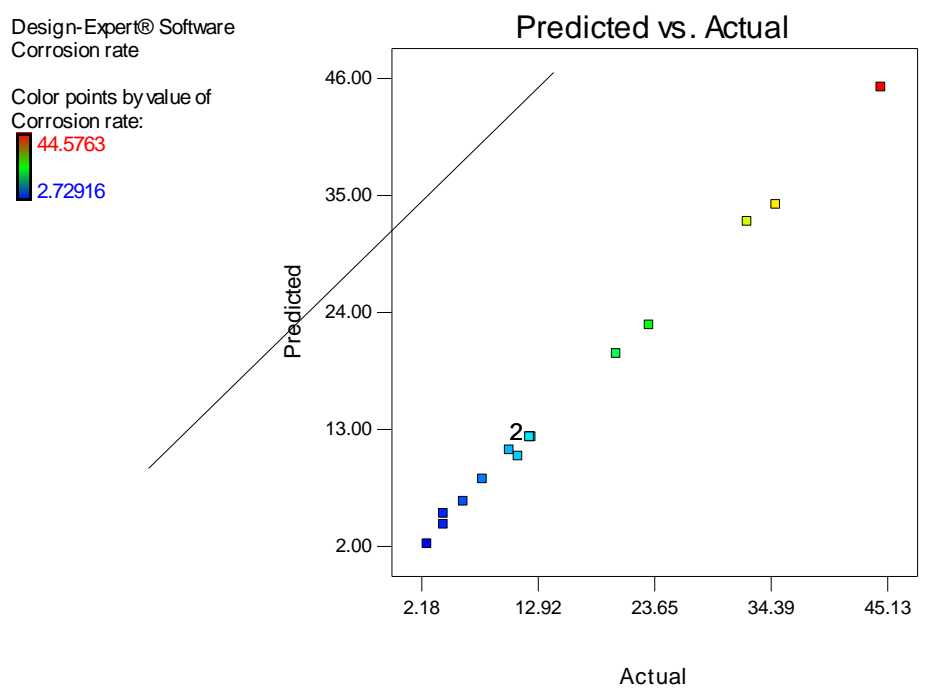

Fig. 2: Predicted values of the model versus the experimental data values.

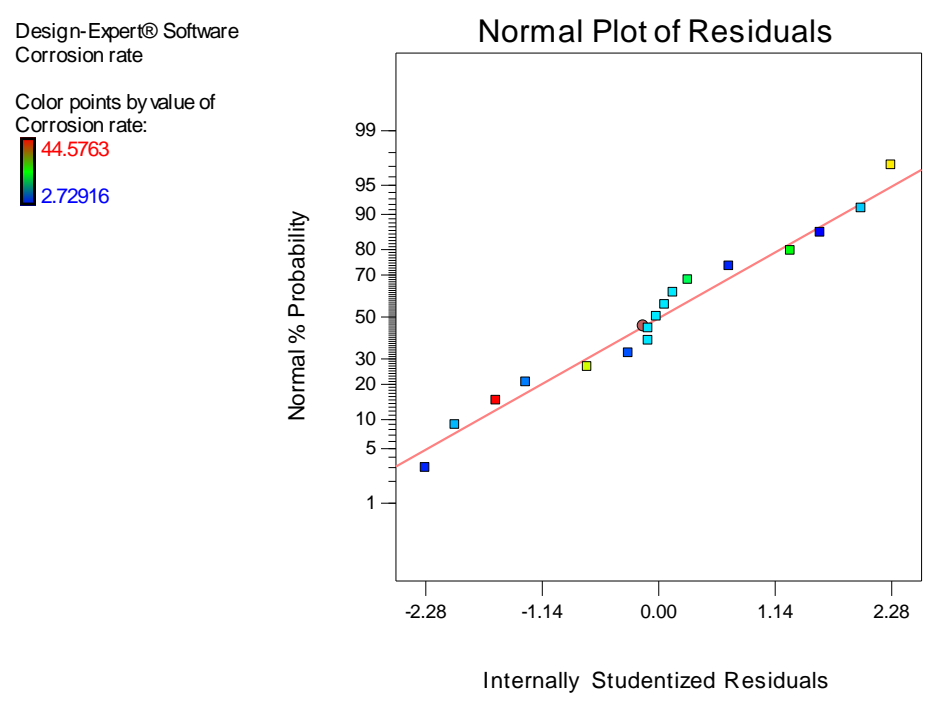

Fig. 3: Normal values of the residuals versus the internally studentized residuals Design-Expert@ Software

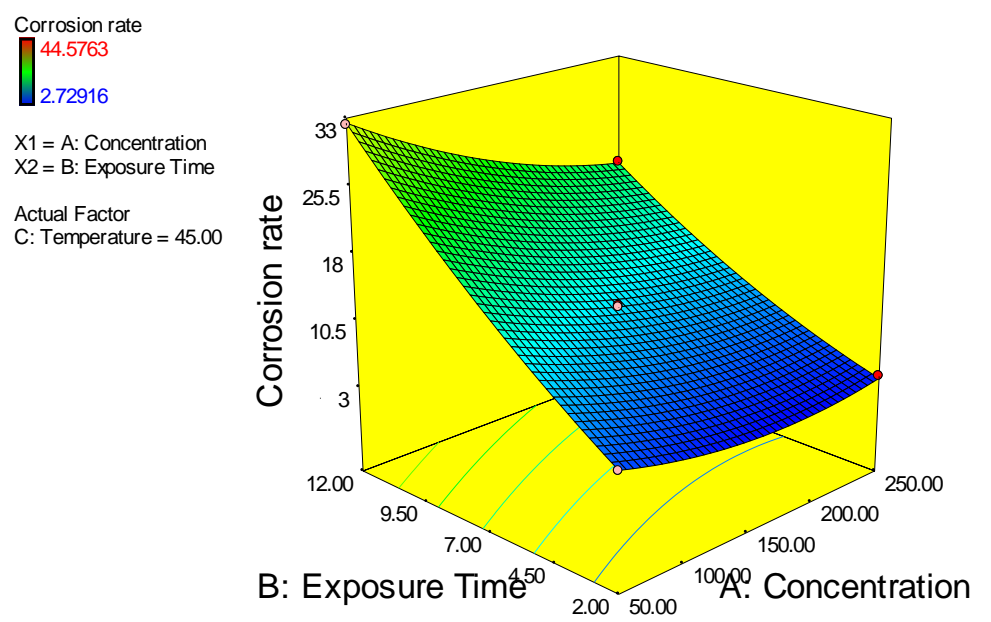

Fig. 4: Surface Plot for the influence of pumpkin pod extract concentration, time, and interface with corrosion rate. 


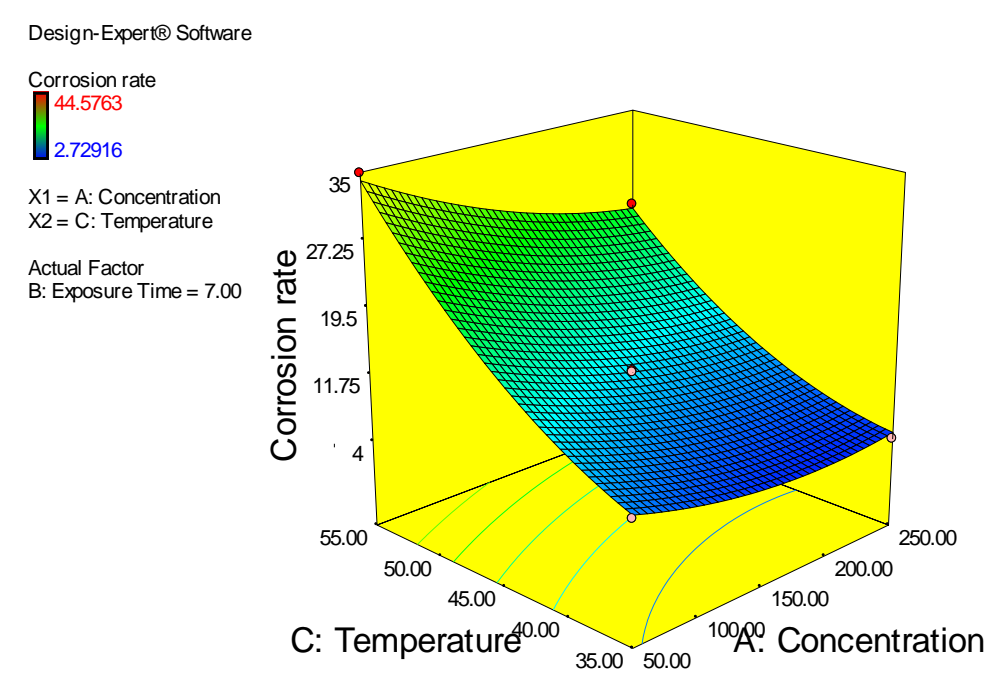

Fig. 5: Surface Plot for the influence of pumpkin pod extract concentration, temperature, and interface with corrosion rate.

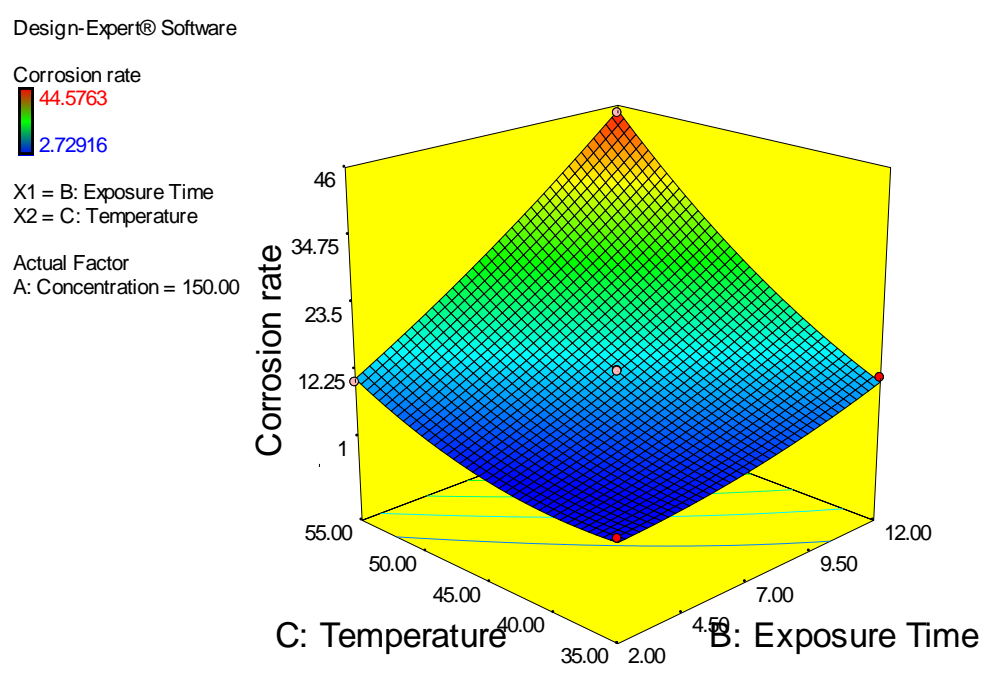

Fig. 6: Surface Plot for the influence of exposure time, temperature, and interface with corrosion rate.

\section{CONCLUSION}

Statistical analysis and optimization of corrosion rate of pumpkin pod extract on carbon steel were carried out in this work. The effects of pumpkin pod extract concentration, exposure time, and temperature on the corrosion rate of carbon steel was determined using Box Behnken design of the Response Surface Methodology (RSM). It was confirmed that all the three process factors considered were all significant but exposure time and temperature showed positive synergy on the rate of corrosion. It was established in this study that pumpkin pod extract inhibit the rate of corrosion on carbon steel as evidenced in the reduced weight loss obtained from the analysis. The second order mathematical model is well fitted to the obtained experimental data. The optimum conditions ascertained was, pumpkin pod extract concentration of $178.07 \mathrm{ppm}, 2.26 \mathrm{hrs}$ of exposure time and temperature of $35.28^{\circ} \mathrm{C}$. This condition was validated in three replicates in the laboratory and rate of corrosion of $2.75 \mathrm{~mm} / \mathrm{yr}$ was achieved. This extract developed for carbon steel corrosion inhibition can be scaled up for industrial application.

\section{ACKNOWLEDGEMENTS}

The authors would like to thank, Mrs. Effi Evelyn, Head, Chemical Engineering Laboratory, Federal University of Petroleum Resources, Effurun, for providing the enabling environment for this work, Mr. Akpeji Honesty, Technologist, Chemistry Department, Federal University of Petroleum Resources, Effurun for his technical assistance. 


\section{REFERENCES}

[1]. Pierre, R. (2008), Corrosion Engineering, Principles and Practice, $2^{\text {nd }}$ ed., New York: Mc Graw Hill,

[2]. Indranil, C. (2009), Fundamental of corrosion and its prevention, In: Industrial Corrosion: Evaluation and mitigation, Jamshedpur: National metallurgical laboratory, 1-18.

[3]. Burton, M. and Kurien, K. C. "Effects of Solute Concentration in Radiolysis of Water", Journal of Physical Chemistry, 63, 1959, 899.

[4]. Elbouchtaoui, M. C. Anejjar, A. Salghi, R. Hmamouchi, M. and Hammouti, B. "Inhibition of steel corrosion in $1 \mathrm{M} \mathrm{HCl}$ by the essential oil of Thymus", Der Pharma-Chemica, 6(4), 2014, $406-414$.

[5]. Akwukwaegbu, P. I. Peters, D. E. and Wegwu, M. O. "Proximate Analysis and Phytochemical Screening of Fluted Pumpkin (Telfairia occidentalis) Pod", American Journal of Food, Nutrition and Health, Vol. 1, No. 1, 2016, 1 6.

[6]. Zhang, Z. M. and Zheng, H. L. "Optimization for de-colourization of azo dye acid green 20 by ultrasound and $\mathrm{H}_{2} \mathrm{O}_{2}$ using response surface methodology", Journal of Hazardous Material, $172,2009,1388$

[7]. Liu, H. L. and Chiou, Y. R. "Optimal decolourization efficiency of Reactive Red 239 by $\mathrm{UV} / \mathrm{TiO}_{2}$ photocatalytic process coupled with response surface methodology", Chemical Engineering Journal, 112, 2005, 173.

[8]. Saidi, M. Hadjadj, M. Ghiaba, M. and Yousfi, M. "Green approach to corrosion inhibition by ethyl acetate extract from Pistaciaatlantica gals in hydrochloric acid solution", Dekmouche, International Journal of Electrochemical Science, 9(7), 2014, 3969 - 3978.

[9]. Benali, O. Selles, C. and Salghi, R. "Inhibition of acid corrosion of mild steel by Anacyclus pyrethrum L. extracts", Research on Chemical Intermediates ,40 (1), 2014, 259 - 268.

[10]. Okeniyi, J. O. Loto, C. A. and Popopla, A. P. I. "Corrosion inhibition performance of rhizophora mangle $L$ bark-extract on concrete steel-reinforcement in industrial/microbial simulating-environment", International Journal of Electrochemical Science, 9 (8), 2014, 4205 4216.

[11]. Chebouat, E. Dadamoussa, B. Gherraf, N. Cheriti, A. and Khiari, A. "Inhibition of Mild Steel Corrosion in $1 \mathrm{~N} \mathrm{HCL}$ Medium by Acid Extract of Ephedra alata", International Journal of
Electrochemical Science, 8 (11), 2013, 12147 12153.

[12]. Leelavathi, S. and Rajalakshmi, R. "Dodonaeaviscosa (L.) Leaves extract as acid Corrosion inhibitor for mild steel - A Green approach", Journal of Materials and Environmental Science, 4 (5), 2013, 625 - 638.

[13]. Zucchi, F. and Omar I. H. "Studies on the inhibitive effect of Occimum viridis extract on the acid corrosion of mild steel", Surface Technology, 24(4), 1985, 391.

[14]. Annadurai, G. and Sheeja, R.Y. "Use of BoxBehnken design of experiments for the adsorption of verofix red using biopolymer", Bioprocess Engineering, Vol. 18, 1998, 463 466.

[15]. Hrdlicka, N. S. Beranek, J. Al-Deyab, S. S. and Salghi, R. "Extract of Phyllanthusfraternus leaves as corrosion inhibitor for mild steel in $\mathrm{H}_{2} \mathrm{SO}_{4}$ solutions", International Journal of Electrochemical Science, 9(6), 2014, 28052815.

[16]. Djeddi, N. Benahmed, M. Akkal, S. Makhloufi, E. and Gherraf, N. "Study on methylene dichloride and butanolic extracts of Reuteralutea (Desf.) Maire (Apiaceae) as effective corrosion inhibitions for carbon steel in $\mathrm{HCl}$ solution", Research on Chemical Intermediates, 2014, 1 $-22$.

[17]. Ghazi, Z. ELmssellem, H. Ramdani, M. Jama, C. and Hammouti, B. "Corrosion inhibition by naturally occurring substance containing Opuntia-FicusIndica extract on the corrosion of steel in hydrochloric acid", Journal of Chemical and Pharmaceutical Research, 6 (7), 2014, $1417-1425$.

[18]. Benmenine, A. E. K. Ouahrani, M. R. Gherraf, N. Sekirifa, M. L. and Baameur, L. "Anticorrosive action study of retamaretam extracts on mild steel X 52 in $20 \% \mathrm{H}_{2} \mathrm{SO}_{4}$ solution", Energy Procedia, 50, 2014, $401-405$.

[19]. Beenakumari, K. S." Saracaindica (Asoka) leaves extract as corrosion inhibitor for mild steel in potable water- A bioremediation method", Journal of Industrial Pollution Control, 29 (2), 2013, $213-218$.

[20]. Uwah, I. E. Okafor, P. C. and Ebiekpe, V. E. "Inhibitive action of ethanol extracts from Nauclealatifolia on the corrosion of mild steel in $\mathrm{H}_{2} \mathrm{SO}_{4}$ solutions and their adsorption characteristics", Arabian Journal of Chemistry, 6 (3), 2013, $285-293$. 
[21]. Ogbonnaya, E. A., and Uadia, P. O. "Phytochemical screening and acute toxicity evaluation of Telfairia occidentalis aqueous extracts on rats", Pakistan Journal of Pharmaceutical Science, Vol. 29, No.3, 2016, $913-917$.

[22]. Nwigbo, S.C. Okafor, V. N. and Okewale, A. O. "Comparative Study of Elaeis Guiniensis Exudates (Palm Wine) as a Corrosion Inhibitor for Mild Steel in acidic and Basic Solutions", Research Journal of Applied Science Engineering and Technology, 4(9), 2012, 1035 - 1039.

[23]. Omoruwou, F. Okewale, A. O. and Owabor, C. N. "Statistical analysis of corrosion inhibition of water hyacinth on mild steel in an acidic medium, Journal of Environmental and Analytical Toxicology", Vol. 7 (4), 2017, 1 - 5.

[24]. Betiku, E. and Adesina, O. A. "The Statistical approach to the optimization of citric acid production using filamentous fungus Aspergillus Niger grown on sweet potato starch hydrolysate", Bioresource Bioenergy 55, 2013, 350-354.

[25]. Joglekar, A. M. and May, A.T. "Product excellence through design of experiments", Cereal Foods World, 32, 1987, 857.
[26]. Mohd, A. A. and Rasyidah, A. "Optimization of malachite green by $\mathrm{KOH}$ - modified grape fruit peel activated carbon: Application of response surface methodology", The chemical Engineering Journal, 2010, 751 - 988.

[27]. Li, W. Waang, Z. Sun, Y. S. Chen, L. Han, L. K. and Zheng, Y. N. "Application of response surface methodology to optimize ultrasonic assisted extraction of four chromones in radix saposhnikoviae", Phytochemical Analysis, 22, $2011,313-321$.

[28]. Rodrigues, R. C. Kenealy, W. R. Dietrich, D. and Jeffries, T. W. "Response surface methodology (RSM) to evaluate effects on corn stover in recovering xylose by DEO hydrolysis", Bioresource Technology, 108, 2012, 134 - 139.

Uwah, I. E., Ugi, B. U., Okafor, P. C., and Ikeuba, A. I., (2013), Comparative study of corrosion inhibition and adsorption characteristics of ethanol extracts of Andrographispaniculata (king bitters) and Vernoniaamygdalina (bitter leaf) on mild steel on $\mathrm{HCl}$ solutions, International Journal of Applied Chemistry, 9 (1), 73 88. 